\title{
Life Education for Young Children in Taiwanese Preschools: Meaning, Aspects and Teaching Methods
}

\author{
Yi-Huang Shih \\ Department of Early Childhood Educare, Ching Kuo Institute of Management and Health, Taiwan
}

Received January 18, 2020; Revised February 25, 2020; Accepted March 12, 2020

Copyright $\bigcirc 2020$ by authors, all rights reserved. Authors agree that this article remains permanently open access under the terms of the Creative Commons Attribution License 4.0 International License

\begin{abstract}
Life education for young children is an important element of education in Taiwan. This kind of education is centered on life care and allows young children to understand the meaning of life and to respect and cherish life. Life education for young children also cultivates kindness and teaches compassion. Young children must develop kindness and be sympathetic to living things around them. This study determines the meaning, various aspects and teaching methods for life education for young children. Firstly, the meaning of life education for young children is explained and then the various aspects of life education for young children are discussed. The teaching methods that are used for life education of young children are: (1) teaching through picture books, (2) learning from experience, (3) teaching through instructional media, (4) teaching using stories, (5) learning by role-playing and (6) teaching via the PTA (Parent and Teacher Association). The emphasis on the importance of life education has been increasing and this study contributes to the development of life education in preschools in Taiwan. Life education classes allow young children to develop a sense of self, a sense of society and a sense of nature.
\end{abstract}

Keywords Life, Young Children, Life Education for Young Children

\section{Introduction}

The 21st century is a time of high technology, which emphasizes utilitarianism, so lives have become materialized. Taiwanese society benefits from advances in science and technology and living standards are increasing. However, society has become a slave to science and technology. Society pays too much attention to science and technology, and ignores the value of human nature (Hsu, 2006).
The Taiwanese education system focuses on the practicalities of science and engineering and neglects humanistic ideals. Post-modern society has seen an increase in the suicide rate for adolescents and the middle-aged. Suicide is a major concern in Taiwan and some do not care about their own lives and other people's lives (Chen, 2004). Life education is increasingly important in current Taiwanese society.

Education seeks to cultivate moral individuals who live a lives of value and meaning and who have spiritual values. Young children are at a key stage of life development. Good life education practices can enhance children's self-awareness and potential. This kind of education teaches children how to have good interpersonal relationships and to develop a sense of responsibility for nature and increases their sense of the value of life. In early childhood, basic knowledge, behaviors and attitudes are established. At this time, life education is more effective. The integration of life education into the curriculum allows young children to feel and experience life through learning, increasing self-knowledge, promoting caring for others, and develops children's sense of responsibility for the environment and for things around them. Teaching practices are important elements of this experience (Shih and $\mathrm{Wu}, 2018$; Wu and Wei, 2010).

Li's study noted that the five most important problems for life education in preschools are: insufficient information about teaching resources, a curriculum that is vulnerable to environmental space, insufficient experience in implementing life education, lack of time and inefficient implementation. Teachers do not know how to teach life education to young children ( $\mathrm{Li}, 2011)$. This study explores the meaning, various aspects and teaching methods of life education for young children, which can allow preschool teachers to effectively deliver the material. A theoretical basis is developed for the praxis of life education for young children, which broadens the vision for this important subject in Taiwan (Shih, Chiang and Chen, 2017). 
This paper determines the place of life education in the Early Childhood Education \& Care Curriculum Framework and explores the meaning and various aspects of life education for young children and the methods for teaching life education to young children in Taiwanese preschools.

\section{Method}

This paper uses the documentary analysis method. Various arguments or events are studied by applying deductive and inductive logic. This paper analyzes studies that are related to life education for young children and uses deductive and inductive logic to determine the best methods of teaching life education to young children (Shih, 2018; Wang, 1991). The empirical research will be explored in subsequent research. This paper only uses the documentary analysis method.

\section{Exploring the Meaning of Life Education for Young Children in Taiwan}

The Early Childhood Education \& Care Curriculum Framework is a guideline for the preschool curriculum and teaching practices in Taiwan. In recent years, early childhood education has flourished and the government has become increasingly concerned about counseling and supplementary programs for early childhood education. The current childcare integration policy was officially launched on January 1, 2012, with the Early Childhood Education \& Care Act and the Early Childhood Education \& Care Curriculum Framework. The Taiwanese government has placed an increasing emphasis on early childhood education (The Ministry of Education, 2017; Wei, 2014).

Early childhood education is the foundation of all later stages of education. The Early Childhood Education \& Care Curriculum Framework is a guideline for preschool education in Taiwan. The Framework seeks to support physical and mental health, develop good habits and an enriched life experience, promote ethical concepts, cultivate gregarious habits, expand the aesthetic experience, develop creative thinking, help to construct a cultural identity for early childhood and inspire a sense of responsibility for the environment (The Ministry of Education, 2017). The last concept listed above is a key part of life education.

The six key areas of the Early Childhood Education \& Care Curriculum Framework are physical movement and health, cognition, language, society, emotion and aesthetic sense, but the element of life education is absent. However, this does not mean that the Early Childhood Education \& Care Curriculum Framework does not apply to the implementation of early childhood life education. This framework uses the educational concepts of benevolence, respect for parents, loving others and caring for the environment. The social field course further encourages young children to develop a sense of themselves, explore their relationship with other people in their living environment, develop their own concepts, interact with others, protect and affirm themselves, respect the living environment and different cultures and develop a responsibility for the living environment and a respect for life (The Ministry of Education, 2017). The Early Childhood Education \& Care Curriculum Framework details the concepts of life education for young children. Preschool teachers must implement these concepts to teach young children to care for themselves, other people and the environment.

Life education for young children enhances young children's respect for life, creates a sense of empathy, promotes self-affirmation and creates a healthy life attitude. Pan (2006) noted that early childhood life education should pertain to both life and death and cultivate young children's ability to live good lives, understand themselves and develop respect for themselves and others. Life education for young children seeks to enhance young children's respect for protecting animals and plants and to cultivate empathy. Life education for young children also seeks to educate the whole person and promote the balanced development of the child's body, mind and spirit so that the child can establish his or her relationship with other people and the environment. The characteristics of life education for young children are detailed below.

\subsection{Diversity}

Life education for young children teaches the diversity of life and death and encourages young children to know themselves and to respect themselves and others. Life education for young children cultivates respect for life, love for life and the protection of animals and plants by cultivating empathy and teaching young children to value natural resources (Shih, Chiang and Chen, 2017).

\subsection{The Whole Person}

Life education for young children involves the whole person and the whole personality and allows young children to establish an equilibrium between heaven, people, things and themselves. It seeks to orient knowledge, emotion and feeling, using the knowledge of young children's lives to encourage a love for life and to develop positive life practices (Shih, Chiang and Chen, 2017).

\subsection{Subjectivity}

The subjectivity of young children is crucial to life education. Life education promotes young children's 
physical and mental health, establishes good living habits, enhances young children's interpersonal relationships and strengthens understanding of ethical concepts (Shih, Chiang and Chen, 2017).

\subsection{Positivity}

Life education for young children teaches children to accept facts that cannot be changed, to overcome predicaments in life and to cultivate a positive attitude when facing problems. When faced with facts that cannot be changed, children are taught to remain calm. Life education for young children teaches them to establish a value of self and affirms the sense of self to allow children to care for themselves, for others and for nature (Shih, Chiang and Chen, 2017).

\section{The Various Aspects of Life Education for Young Children}

\subsection{I and Myself}

This includes knowing oneself, knowing one's own uniqueness and learning to understand personal interests, abilities and traits. Appreciation and acceptance involves appreciating one's strengths, accepting weaknesses, affirming one's self-worth and developing an ability to perceive oneself. Development of the self involves developing one's own qualities and potential (Wu, Huang, Chan, Hsaio and Wu, 2007)

\subsection{Humans and Society}

This involves a cultivation of empathy. When faced with different ethnic groups, genders and cultures, children learn to experience and respect pluralistic values and develop the ability to situate and empathize, and develop an appreciation and acceptance of others by appreciating the strengths and weaknesses of others. Respect and caring involves caring for others in need and creating harmonious interaction between individuals.

Forgiveness and tolerance involves cultivating tolerance and changing attitudes of prejudice and discrimination. This cultivates ethical care for young children to help them gain an inclusive understanding of society in the future (Wu, Huang, Chan, Hsaio and Wu, 2007).

\subsection{Human and Nature}

This involves appreciating and loving nature by being close to nature, discovering the beauty of nature and caring for natural life. Sustainable management of nature involves realizing the importance of cherishing nature by observing ecological changes and thinking about environmental issues (Wu, Huang, Chan, Hsaio and Wu, 2007).
Environmental issues and human sustainability are a focus for humanity's sustainable survival, and sustainable development is an important idea in environmental education (Jickling, 2005).

\section{Teaching Methods of Life Education for Young Children in Taiwanese Preschools}

\subsection{Teaching through Picture Books}

Picture books have a graphic form, so the readers can imagine the development of the story, which inspires the imagination. A picture book provides knowledge and can be used to transfer concepts and to give emotional guidance (Hsiau, 2002). Teaching using picture books stimulates compassion for other people in young children.

Picture books foster sympathy and empathy in young children and a child-oriented life education curriculum that uses picture books is suited to young children of preschool age (Hsiau, 2002). Story plots promote the development of compassion and empathy. When young children try to experience the feelings of the characters in a picture book, they develop compassion and empathy. When an unfortunate encounter results in suffering, sympathy and caring are fostered.

\subsection{Learning from Experience}

Life education for young children involves learning by doing and learning from experience. The use of experience as a teaching strategy for life education allows the teacher to relate to the child. Experience allows young children to determine the value of life and activities such as planting and nurturing cultivate young children's respect for life and concern for animals and plants (Hsiau, 2002). Integrating experiential activities into life education increases empathy and caring behavior. Reflection after the experience allows young children to verify their feelings (Fang, 2012).

Young children are in Piaget's Sensorimotor Stage and Preoperational Stage of development but they also engage in higher-level cognitive thinking, even though they lack the life experience of adults, so experiential teaching is beneficial. Learning through experience has a significant effect on young children. Wu (2006) noted that teachers should give young children more opportunities to experience life. A dogmatic narrative does not allow young children to understand the abstract meanings of reason, religion, morality and philosophy. Life education for young children must focus on individual experience. Young children must learn through practical experiential activities that allow them to share experiences and think about the results. Preschool teachers must use experience to teach life education to young children. 
Finally, using experience activities, e.g., breaking through obstacles, preschool teachers can allow young children to form a group of two, one of whom wears a blindfold and listens to instructions, while the other makes sounds such as clapping or tapping an instrument to direct the child to a specified position. The two exchange and experience different feelings. The teacher then asks the young children how they feel when they wear a blindfold and they are surrounded by darkness or how they feel when someone is pulling them forward. This allows an exploration of how to overcome psychological fear and of the thought process that allows the child to deal with problems. During this exercise, young children experience the problems of blind people, learn to understand blind people's problems and then develop their own behavioral rules for when they meet blind people in the future. Combining experiential activities with young children's life experience allows young children to integrate feelings and experiences and to internalize appropriate life values.

Daily life involves the accumulation of self-experience. Experiential activities combine the experiences of others with self-experience. However, if the feelings after the experience can be transformed into a systematic and clear concept, there must be sufficient time for young children to organize, share and discuss the feelings. It is important for young children to transform emotional connections into beliefs through sharing and discussion and to practice these beliefs in daily life. This process allows the teaching of life education to be effective and meaningful for the young children.

\subsection{Teaching through Instructional Media}

Instructional media are defined as anything that is used to send information from the sender(s) to the receiver(s) to increase learners' curiosity and encourage them to learn. In terms of this definition, instructional media includes all of the traditional methods that are used to deliver the lesson (teachers, chalkboards, textbooks, and other printed materials) or new instructional media (CD ROM, computers, interactive video and multimedia systems). This study defines instructional media as tools that are used in an educational setting to deliver the materials and information that result in effective teaching and learning (Tanti Sukmahidayanti, 2015).

Advances in science and technology and in teaching resources mean that audio-visual teaching media have become common in preschool teaching. The use of appropriate teaching media achieves the best teaching results. Pan (2006) noted that using media teaching materials increases young children's interest in learning. The use of films as a teaching medium for early childhood life education increases young children's awareness of life (Hsieh, 2008). The concept of death comes from the media (Hsiau, 2002). In terms of the use of film as a teaching medium, Hsieh (2008) noted that the films that are used must be appropriate to the teaching objectives and must promote young children's cognitive development.

\subsection{Learning Using Stories}

A story amuses children and reinforces memories for young children. Since the development of human language, storytelling has been an important element of life for transmitting culture, as a means of mass entertainment and religious communication, or as an educational tool (Wu and Wei, 2007).

A story also conveys human history and experience. A story is an alternative to a lullaby for young children. Stories that are heard in childhood imprint deep memories. Stories are also used to educate the next generation and to communicate love for young children. Storytelling decreases the distance between adults and young children, and strengthens their relationship. Adults must tell stories to young children, engage with young children as they develop and encourage young children to appreciate the beauty of pictures and words by telling stories.

The American educator, Parker, noted that children like fairy tales mostly because fairy tales cushion harsh reality in an alternative world that children create in their imagination (Parker, 1969). Young children like listening to stories and the more diverse the story, the better. Pan (2006) noted that children must be motivated to learn from stories, so stories are a useful teaching medium for the life education of young children.

\subsection{Learning by Role-Playing}

Role-playing, like socio-drama, is derived from psychodrama. Psychological drama was founded around 1920 by J. D. Moreno. After many amendments and changes, it is currently a treatment method in the field of counseling and is regarded as an effective group counseling technique. Moreno defined role-playing as being in the position to play a role that is not one's own in real life. Moreover, children learn from role models through continuous exercises, to increase flexibility in dealing with the living environment. Teaching using role-play is an important and practical method. Using stories or problems, young children learn to explore feelings, attitudes, values and problem-solving strategies. Young children also learn to understand others through role-playing. Preschool teachers should use role-playing to allow young children to experience and learn, which stimulates motivation and increases interest in learning. Performances allow a high degree of participation and make teaching activities more lively (Chen, Yang and Su, 2007).

\subsection{Teaching via the PTA}

To increase the effectiveness of learning and improve the quality of education, schools must strengthen their 
partnership with parents and society. This relationship is called parent-teacher cooperation in Taiwan, home-school cooperation in China and PTA (Parent and Teacher Association) in Europe and America. Furthermore, the theoretical foundation and function of a PTA is that of a formal organization composed of parents, teachers and staff that is intended to facilitate parental educational participation in schools. The concept emphasizes children or adolescents as the future hopes of a country and society. They grow up in the family, grow up in school and achieve in society. The family (parents), the school (teachers) and society (adults) influence children's learning so parents and teachers must cooperate to guide children, so that they will be better able to face the future ( $\mathrm{Li}, 2013)$.

Parent-teacher cooperation is an important bridge for young children's life education in terms of the development of young children's concepts of life and self. Family education is an important part of life education. Preschool teachers must make good use of parental resources (Pan, 2006). Preschool teachers should be encouraged to develop appropriate elements of life education courses for parents and young children, such as to allow parents and young children to grow together. For example, parents and children can observe and record the growth of flowers and preschool teachers can share the concepts of life education with parents on parents' day.

\section{Conclusions and Results}

\subsection{Conclusions}

Children must try various types of activities. They are not latent creatures. Adults must approach them cautiously and enhance latent skills and talents. Children are extremely active so education must use the child's activities to give guidance. Guided and organized teaching activities can produce valuable results (Dewey, 1900). Preschool teachers can also produce valuable results by using teaching content for preschool life education in a guided and organized manner. Young children's life education should value the concept of life so that young children engage with life.

\subsection{Results}

Understanding the meaning, various aspects and teaching methods of life education for young children can increase the quality of life for these children. Life education for young children cultivates positive life attitudes, including respect, care and love.

The aspects of life education for young children include I and Myself, Humans and Society and Humans and Nature. The teaching methods of life education for young children are also detailed. Teaching is an important part of life education. This study explores these methods and makes recommendations for preschool teachers, in order to increase the quality of teaching within life education. The most effective teaching methods involve:

\subsubsection{Teaching Using Picture Books}

Young children like picture books. There are many vivid pictures in picture books, which can increase young children's learning motivation and interest. For this reason, picture books can provide a practical way to give young children knowledge of life. This method is worth applying for teachers who are teaching life education to young children.

\subsubsection{Learning from Experience}

Combining experiential activities with young children's life experience allows young children to integrate their feelings and experiences and to internalize appropriate life values. The designs of young children's life education curriculum should be closely integrated with children's life experiences so that the curriculum can be truly and vividly presented in teaching praxis.

\subsubsection{Teaching through Instructional Media}

The use of teaching media in young children's life education creates vivid and realistic learning scenarios, which can increase young children's learning motivation and interest, and let them feel that learning is not a boring activity.

\subsubsection{Teaching Using Stories}

Classic children's stories cultivate young children's character and temperament. This is the first step in cultivating wisdom for life in young children. Incorporating stories into life education of early childhood can enhance discussion with young children and let young children feel and recognize the essence of life.

\subsubsection{Learning by Role-Playing}

Young children like role-playing games. They may play as a teacher, a parent, a shop assistant, or any role that they know. The role-playing process teaches young children how to cooperate and socialize and care for other people, and even care for their living environment.

\subsubsection{Teaching via the PTA}

Parent-teacher communication is an important bridge for young children's life education and family education is an important part of young children's life education. Parents must be involved in life education for preschool children. Parental resources are also an important element in the teaching of life education for young children. Early childhood life education requires parent-teacher cooperation, and this cooperation cultivates young children's abilities to face their own lives and meet the challenges of future life.

Finally, modern society advocates utilitarianism, and it 
is very important for young children to learn to take care of themselves, to take care of others and their environment through life education. Huang, Wei and Hong (2011) noted that teaching life education for young preschool children exploits the golden age of early childhood. Effectively designed teaching activities and family education increase young children's self-affirmation and respect for others and the natural environment. This study shows that life education is important for young children in Taiwan and makes recommendations for teaching life education to young children that we should increase the scope of this kind of education for these students. Practical recommendations are made to improve life education classes in Taiwanese preschools to allow young children to develop harmoniously in the areas of I and Myself, Human and Society and Human and Nature.

\section{REFERENCES}

[1] L. Y. Chen. The development of life education in Taiwan, Philosophy and Culture Vol.31, No.9, 21-46, 2004.

[2] R. C. Chen, J. X. Yang, Z. Y. Su. The exploration of role-playing teaching method in the network synchronous teaching environment. Life Science Education Monthly, Vol.40, No.5, 3-13, 2007.

[3] J. Dewey. The school and society. In J. A. Boydston (Ed.) The Middle Works, Vol. 1, pp. 1-112. Carbondale, IL: SIU Press, 1900.

[4] L. Y. Fang. The action research of life education for early childhood - A case of nature experience activity in school (Unpublished master dissertation). Taipei, Taiwan: National Taipei University of Education, 2012.

[5] K. Hsiau. Research on children's life education teaching and practice (Unpublished master dissertation). Taipei, Taiwan: Taipei Municipal Teacher Normal College, 2002.

[6] C. S. Hsu. Humanism education concept in Italy. Tzu Chi Journal of Educational Research, Vol.2, 1-32, 2006.

[7] B. Y. Huang, W. T. Wei, Z. L. Hong. Analyzing preschool teachers' attitudes towards life education and experimental research on the effects of life education. Journal of Education Studies, Vol.45, No.2, 59-85, 2011.

[8] B. Jickling. Sustainable development in a globalizing world: a few cautions. Policy Futures in Education, Vol.3, No.3, 251-259, 2005.

[9] M. C. Li. A study of life attitude and implementation of life Education for early childhood teachers (Unpublished master dissertation). Taichung, Taiwan: Chaoyang University of Technology, 2011.

[10] J. X. Li. The strategy and vision of parents and teachers work together. Taiwan Education, Vol.682, 21-24, 2013.

[11] F. W. Parker. Talks on pedagogics. New York: Arno Press, 1969.
[12] Y. C. Pan. Multimedia teaching application in children's life education research self-concept (Unpublished master dissertation). Taipei, Taiwan: National Taipei University of Education, 2006.

[13] Y. H. Shih, Y. M. Chiang, P. Y. Chen. Life Education for young children: Meaning, content, aim, praxis, and reflection. Journal of Early Childhood Education \& Care, Vol.18, 29-46, 2017.

[14] Y. H. Shih, P. F. Wu. Let life tell stories: A study of the content of life education for young children. The Journal of Ching Kuo, Vol.34, 1-11, 2018.

[15] Y. H. Shih. Towards a pedagogy of humanizing child education in terms of teacher-student interaction. Journal of Education and Learning, Vol.7, No.3, 197-202, 2018.

[16] T. Sukmahidayanti. The utilization of instructional media in teaching English to young learners (A case study of an elementary school teacher in Bandung). Journal of English and Education 2015, Vol.3, No.2, 90-100, 2015.

[17] The Ministry of Education. The early childhood education \& care curriculum framework. Taipei, Taiwan: The Ministry of Education, 2017.

[18] W. K. Wang. Educational research methods. Taipei, Taiwan: Wu-Nan Book, 1991.

[19] M. H. Wu. Modern preschool education thoughts. Taipei, Taiwan: Psychology, 2014.

[20] C. K. Wu, S. C. W. On principle of story teaching from psychological reaction of Story Listening, The Journal of Educational Science, Vol.7, No.1, 15-35, 2014.

[21] S. S. Wu, C. J. Wei. The vitality of early child's picture books - To explore the content and teaching targets of early childhood life education picture books, Journal of Early Childhood Education \& Care, Vol.4, 19-33, 2010.

[22] S. S. Wu, L. H. Huang, W. K. Chan, Y. Y. Hsaio, Y. C. Wu. The Ministry of Education's 95-year plan for developing curriculum and teaching indicators for life education. Taipei, Taiwan: The Ministry of Education, 2007.

[23] Y. S. Wu. The research of elementary life education curriculum design and practice (Unpublished master dissertation). Hsinchu, Taiwan: National Hsinchu University of Education, 2006. 